\title{
Fostering Digital Literacy through Web-based Collaborative Inquiry Learning - A Case Study
}

\author{
FU Jun \\ School of Educational \\ Technology, South China \\ Normal University, P. R. China
}

Fujunscnu@yahoo.com.cn

\author{
Jacky POW \\ Department of Education \\ Studies, Hong Kong Baptist \\ University, HKSAR, P. R. China
}

\section{Executive Summary}

Digital literacy (DL), a term that emerged with the explosion of digital information and multimedia technology, refers to basic competence in using digital technology. The present study first analyzed the evolvement from media literacy to digital literacy and developed a four-branch theoretical framework of DL by investigating related definitions of it. For the purpose of fostering DL, a set of web-based collaborative inquiry learning (WCIL) activities was designed and were implemented on weblog to further the DL of secondary 3 students (aged 14 to 15). To provide students with the necessary support and facilitate their progress, eight fortnightly lessons of one to one and a half hours each were arranged, at which students were asked to report/present the latest progress of their WCIL project, and their teacher gave suggestions and offered the students resources to deal with the problems they had encountered.

The purpose of this study was to explore the effects of the WCIL activities on student DL levels and the problems that might be encountered by students and teachers in carrying out the activities. Data were collected from a variety of sources, including lesson observations, focus group interviews, and student weblog postings.

The findings show that (1) the WCIL activities were useful in involving students in DL practices and improved student DL levels across a wide variety of indicators, and (2) problems in the implementation of the WCIL activities included inexperience in collaborative inquiry learning, insufficient leadership skills of group leaders, and inadequate DL, which was mainly embodied as the difficulties that the students had in analyzing and synthesizing inquiry materials and improving the level of their accuracy in accessing information.

In addition to their development in DL, students also reported social benefits obtained through WCIL, which was embodied as their improvement in collaborative ability, interpersonal skills, leadership skills, articulacy, ability to adapt, judgment, and the courage to carry out interviews

Material published as part of this publication, either on-line or in print, is copyrighted by the Informing Science Institute. Permission to make digital or paper copy of part or all of these works for personal or classroom use is granted without fee provided that the copies are not made or distributed for profit or commercial advantage AND that copies 1) bear this notice in full and 2) give the full citation on the first page. It is permissible to abstract these works so long as credit is given. To copy in all other cases or to republish or to post on a server or to redistribute to lists requires specific permission and payment of a fee. Contact Publisher@InformingScience.org to request redistribution permission. and surveys with strangers. Given these benefits, this study only represents a single case, and thus the findings may not be replicable in other educational settings. Further studies are needed to clarify the effect of WCIL on student DL.

Keywords: Digital literacy, Web-based, Collaborative learning, Blog, Inquiry learning 


\section{Introduction}

Tapscott (2009) claims that children today are so accustomed to digital technology that they think it is part of the natural landscape. However, many problems related to their use of such technology have emerged, including Internet addiction (Young, 1996), lack of web literacy (Kuiper, Volman \& Terwel, 2009), Internet bullying (Campbell, 2005), illegal downloading, and other related problems. It is apparent that children need to develop a new kind of literacy to enable them to function effectively in the digital era. This literacy is recognised by Eshet-Alkalai and \& Amichal-Hamburger (2004) as digital literacy (DL).

With digital technology permeating all aspects of our lives, DL and its development have received much attention recently. For example, DL takes a central place in several of the European Union's research and education programs (Soby, 2008), while the European Commission (2003) regards DL as a prerequisite for creativity, innovation, and entrepreneurship. DL is also one of the eight key competencies cited in the Recommendation of the European Parliament and the Council of the European Union on key competences for lifelong learning (European Union, 2006). Much research and practical work suggests that collaborative inquiry learning activities carried out in a digital environment, or web-based collaborative inquiry learning (WCIL), constitutes a useful approach to foster DL among students (Doering, Beach, \& O’Brien, 2007; Erstad, Gilje, \& Lange, 2007; Hartley, McWilliam, Burgess, \& Banks, 2008; Kuiper et al., 2009; Luce-Kapler, 2007; Midoro, 2007; Owston, Wideman, Ronda, \& Brown, 2009; Soby, 2008). However, two major questions remain unanswered: what effect have these learning activities on the development of DL among students, and what problems may appear during the process of WCIL? This study will try to answer these questions through a systematic investigation of WCIL activities carried out in a real school setting.

\section{Theoretical Framework}

\section{From Media Literacy to Digital Literacy}

Media literacy has traditionally meant being a wise consumer of mass media. The Association for Media Literacy (AML) states on its website that media literacy involves helping students to develop an informed and critical understanding of the nature of mass media, the techniques that they use, and the impact of these techniques. Ultimately, it aims to foster an understanding of various media, which includes knowledge of their strengths and weaknesses, biases and priorities, role and impact and artistry and artifact.

With the advancement of media technology and the changes it has brought to our culture, the definition of media literacy has evolved. As media convergence and read-write web have become two of the most noticeable features of the present digital age, media literacy has changed from stressing demystification to balancing demystification and creation (Buckingham, 2003). Media literacy implies having access to, understanding of, and creating/expressing oneself using media (Horton, 2007). Ofcom (2009) extends this tripartite relationship and defines media literacy as the ability to access, understand, and create communications in a variety of contexts. From this perspective, the term "digital literacy" better describes literacy in the digital age and stresses the balance of demystification and creation of media in the context of digital media convergence.

\section{Digital Literacy}

DL is a comparatively new concept that reflects the requirement of user ability in the digital era; its definition has thus evolved with the development of technology. In the early stage of research into DL, it was defined as "the ability to understand and use information in multiple formats from a wide range of sources when it is presented via computers" (Gilster, 1997, p.1). The Educational 
Testing Service of America (2002) uses the term "digital competence" to refer to a combination of knowledge, skills, and attitudes, which involves the confident and critical use of information society technologies for work, leisure, and communication. Eshet-Alkali and Amichal-Hamburger (2004) argue that the current conception of DL has extended to integrate the technical, cognitive, motor, sociological, and emotional skills that users need to acquire in order to use digital environments effectively. Martin (2008) developed a definition rooted in his analysis of the existing DL definitions:

Digital Literacy is the awareness, attitude and ability of individuals to appropriately use digital tools and facilities to identify, access, manage, integrate, evaluate, analyze and synthesize digital resources, construct new knowledge, create media expressions, and communicate with others, in the context of specific life situations, in order to enable constructive social action, and to reflect upon this process. (p. 167).

Based on the foregoing definitions, we have identified four branches of DL:

A1. The ability to collect, evaluate, analyze and synthesize multimedia digital text;

A2. The ability to create multimedia artifacts;

A3. The ability to carry out online communication; and

A4. The awareness, attitude and ability to use digital technology (including digital tools, facilities and resources) appropriately (legally, ethically, safely and responsibly).

\section{Design of the Learning Activities}

Collaborative inquiry learning aims at bringing about a culture in which students in groups are motivated to engage in self-regulated learning activities supported by the teacher (Bell, Urhahne, Schanze \& Ploetzner, 2010). With reference to the work of Doering et al. (2007), Erstad et al. (2007), Hartley et al. (2008), Kuiper et al. (2009), Luce-Kapler (2007), Midoro (2007), Owston et al. (2009), and Soby (2008), and the collaborative inquiry model put forward by Chang, Sung and Lee (2003), a set of web-based collaborative inquiry learning (WCIL) activities was designed to foster student DL (see Figure 1). Among the Web based collaborative learning activities, many of them are based on a group weblog.

1. Collaborate on identifying a group inquiry topic through collecting related reference information (multiformat information is encouraged)

2. Generate inquiry questions through collaboration and discussion, and post them on the group weblog

3. Formulate an inquiry plan collaboratively and post it on the group weblog

4. Implement inquiries through the efforts of the whole group (gathering data based on the inquiry questions)

5. Organize and analyze data through collaboration, present the collated material and analyze the results on the group weblog

6. Compose a digital inquiry report through cooperation and collaboration, and post it on the group weblog (multimedia expression is encouraged)

\section{Figure 1 WCIL activities}

Weblogs are web-based journals that are updated regularly, contain text and visual entries that are displayed in reverse chronological order (Lui, Choy, Cheung \& Li, 2006), and are publicly accessible. As they can encourage personal reflection, critical thinking, and rigorous writing composition and are easy to use, in this study weblogs were employed to serve as virtual platforms where 
students could collaborate with group members, share their inquiry data, record their online inquiry learning process, and publish their inquiry learning reports.

All of the WCIL activities were implemented in a real school setting for the purpose of DL development. The participants were divided into groups and required to engage in these activities to inquire into the topic in which they were interested. They were required to complete all six activities on computers and on the Internet after class.

The WCIL activities lasted for almost a whole semester (about four months). To provide students with the necessary support and facilitate their progress, eight fortnightly lessons of one to one and a half hours each were arranged, at which students were asked to report/present the latest progress of their WCIL project, and their teacher gave suggestions and offered the students resources to deal with the problems they had encountered. Figure 2 shows the content of these lessons.

\begin{tabular}{|c|c|}
\hline $\begin{array}{l}\text { Lesson } \\
1\end{array}$ & $\begin{array}{l}\text { Preparation } \\
\text { 1. Groups are formed } \\
\text { 2. Google accounts and group weblogs are set up } \\
\text { 3. Teacher gives a general introduction to the WCIL project }\end{array}$ \\
\hline $\begin{array}{l}\text { Lesson } \\
2\end{array}$ & $\begin{array}{l}\text { Information accessing } \\
\text { 1. Teacher discusses information searching skills using search engines } \\
\text { 2. Teacher outlines copyright and requirements for information use } \\
\text { 3. Teacher introduces Creative Commons rules, features and usages }\end{array}$ \\
\hline $\begin{array}{l}\text { Lesson } \\
3\end{array}$ & $\begin{array}{l}\text { Introduction to inquiry learning projects } \\
\text { 1. Teacher introduces the principles of choosing a topic (development of an in- } \\
\text { quiry topic) } \\
\text { 2. Teacher analyzes the typical process of an inquiry learning project } \\
\text { 3. Teacher lists the tasks that students need to accomplish } \\
\text { 4. Teacher outlines the criteria of a good inquiry learning project }\end{array}$ \\
\hline $\begin{array}{l}\text { Lesson } \\
4\end{array}$ & $\begin{array}{l}\text { Proposed topic presentation } \\
\text { 1. Students present their proposed inquiry topic collaboratively } \\
\text { 2. Students and the teacher comment on topics, and give suggestions to each } \\
\text { group } \\
\text { 3. Students work collaboratively to generate inquiry questions and choose an } \\
\text { inquiry method, and write an inquiry learning plan that includes the topic and } \\
\text { background information, purpose of the inquiry, proposed inquiry questions (in- } \\
\text { quiry focus questions), time schedule and inquiry methods, information/data } \\
\text { collection methods and analysis approach, possible difficulties and limitations, } \\
\text { significance of the inquiry, references, and so forth }\end{array}$ \\
\hline $\begin{array}{l}\text { Lesson } \\
5\end{array}$ & $\begin{array}{l}\text { Presentation of the inquiry plan } \\
\text { 1. Each group presents its inquiry plan to the class } \\
\text { 2. Teacher gives suggestions on plan revision }\end{array}$ \\
\hline $\begin{array}{l}\text { Lesson } \\
6\end{array}$ & $\begin{array}{l}\text { Criteria of a good inquiry study } \\
\text { 1. Teacher analyzes typical WCIL activities with students (including the we- } \\
\text { blog, inquiry plan and inquiry report) } \\
\text { 2. Teacher and students evaluate typical inquiry learning projects to understand } \\
\text { the inquiry process } \\
\text { 3. Teacher leads students to understand the criteria of a good inquiry learning } \\
\text { project }\end{array}$ \\
\hline
\end{tabular}




\begin{tabular}{|l|l|}
\hline Lesson & $\begin{array}{l}\text { Progress report } \\
\text { 1. Ten groups share their progress in inquiry reports, in which they present the } \\
\text { data collected, finished and unfinished items and existing problems } \\
\text { 2. Students and the teacher give suggestions on how to process data, organize } \\
\text { content and finish the inquiry learning reports }\end{array}$ \\
\hline \begin{tabular}{l|l} 
Lesson \\
8
\end{tabular} & $\begin{array}{l}\text { Final presentation and debriefing } \\
\text { 1. Ten groups present their inquiry reports } \\
\text { 2. Discussion among the teacher and peers; debriefing }\end{array}$ \\
\hline
\end{tabular}

Figure 2 Content of the eight tutorial lessons

\section{Methods}

\section{Design of the Study}

The WCIL activities described above were implemented in a course named "Inquiry Learning," which was offered by a local Hong Kong secondary school. The present case study was based on the observation of the performance of the activities. The course was designed to prepare secondary 3 students for Liberal Studies (a new core senior secondary subject that counts towards university admission) in secondary 4. Forty-two students (aged 14 to 15) from a secondary 3 class participated in this study. Two reasons are behind their selection: first, secondary 3 students have basic computer skills but need further DL training; second, they are relatively free from the pressure of entrance examinations for senior secondary school, which means researchers have more latitude to implement new pedagogies and experiences. The teacher of the "Inquiry Learning" course was invited to implement the proposed WCIL activities, and the participants were divided into 10 groups of four to five students to perform the activities.

The secondary school from which the participants were chosen is a government-aided local school. Although students in this secondary school are not typically those with outstanding academic performance, they are very active and creative in digital media expression. The school stresses the comprehensive development of the moral, intellectual, physical, social, and aesthetic abilities of students. In addition to the basic academic subjects, the school curricula include many practical options (e.g., home economics, design, and technology) and humanities subjects (e.g., visual arts, music) to provide students with a holistic education. Innovation and diversified development are encouraged. Equipped with a campus TV station and other information and communication technology (ICT) facilities, the school provides students with a creative learning environment. In fact, a few of the participants in this study ran the campus TV station. Most of the students had their own computers with Internet access at home, and many had a digital camera or digital video camcorder. In summary, these favorable circumstances ensured the easy access of students to digital technologies.

\section{Data Collection and Analysis}

The research data were collected mainly through lesson observation and focus group interviews, while the weblog postings of students provided an important supplementary data source.

All eight tutorial lessons were observed, with holistic field notes taken, to investigate the problems that students met in WCIL and the effect of the teacher's instruction on student DL. Two semi-structured focus group interviews were conducted to find out the effect of WCIL on student DL and the difficulties that students met in completing the WCIL activities. The first interview was conducted after all of the groups had finished formulating their inquiry plans; the second was done after students had finished their digital inquiry reports. Both of the interviews were led by the researcher, who acted merely as a facilitator in the focus group discussion by putting forward 
the necessary neutral questions to explore or clarify the discourse of students. The students who participated in the focus group interviews comprised those who acted as leaders in the ten learning groups. The focus group interviews concentrated on 1) the changes that had taken place in the DL skills and attitudes of students, and 2) the difficulties that students encountered during WCIL. Figure 3 shows the questions discussed in the interviews.

1. What problems or difficulties has your group encountered in WCIL? What do you think is troublesome for you during WCIL?

2. What changes have taken place in your ability to collect, evaluate, analyze, synthesize, create and communicate multimedia digital text during WCIL?

3. What changes have occurred during WCIL in your ability to present your inquiry learning results using multiformat digital texts?

4. Can you tell proper from improper behavior in relation to the use of digital technology? Have your criteria to judge such behavior changed during WCIL? Has your ability to limit yourself to the proper use of digital technology changed during WCIL?

5. What else have you learned from WCIL?

Figure 3 Question list for the semi-structured focus group interviews

ATLAS.ti was used to analyze the transcriptions of the focus group interviews. A range of themes was generated, based on which codes were made. The themes were "DL improvement," "Growth in inquiry learning ability," "Personal development" and "Problems encountered," and the codes under each theme were grouped into sub-themes to present the concrete details of the theme. The codes were named after the group leader who had revealed the content of the code. For example, if a code was derived from the discourse of the leader of group 5, it was named GL5.

Data were collected from student postings on the group weblogs, which served as records of the WCIL activities of the students and the external representation of their DL. Content analysis was undertaken to identify an important part of DL - information accessing behavior. All of the information that students cited on their weblogs was categorized into five types according to the source: (1) government, university and organization websites; (2) online encyclopedias, such as Wikipedia and Yahoo Knowledge; (3) portals (SINA, Yahoo, and so forth); (4) business websites; and (5) weblogs, bulletin board system (BBS) forums and personal websites. The categorization was done respectively by the researcher and a research postgraduate student from the University of Hong Kong. Cohen's kappa coefficient, a statistical measurement of inter-rater agreement, was obtained, and its value of $70.01 \%$ indicates substantial inter-rater reliability. The relative proportions of the five types of information sources illustrate the information accessing and evaluation behavior of the participants. In addition, the number of expressive modes (video, audio, picture or text) used in the inquiry reports of students were counted and the frequency of usage of each mode was calculated. The results indicate students' level of ability to create multiformat media artifacts, and can also provide a means of triangulation through comparison with the focus group interview data.

\section{Results}

\section{Improvement in Digital Literacy}

In the reflective writings of students on the group weblogs, almost all of the participants said that WCIL is a fruitful study process, while their gains varied. Those who had daily exposure to digital technologies felt that their collaboration and inquiry learning skills had improved significantly, while those who had less such exposure felt that their improvement in DL was more apparent. 
The students were required to complete all of the work for an inquiry learning task using digital technologies, and thus both their DL skill levels and attitudes improved. A typical example is that of a female student, who can now input Chinese characters at a keyboard with ease instead of using handwriting recognition devices. In the following paragraphs, all of the codes related to DL improvement are clustered into four subsets, which are listed according to the definition of DL to show the effect of WCIL in fostering student DL.

\section{Improvement in the Ability to Collect, Evaluate, Analyze, and Synthesize Multimedia Digital Text}

First, WCIL facilitated the development of information collection and use strategies by participants. The students reported that through collecting inquiry materials for the WCIL activities, they were able to get access to online information with greater ease.

GL8: Generally, when we search for certain information, we are more likely to go to some authoritative websites to get some basic information first. Then we go to search engines, such as Google or Yahoo, to find more supplementary information.

The students also developed strategies for collecting materials. Of the information sources quoted in their weblogs, $25 \%$ of the links were from government or library websites, $18 \%$ from online encyclopedias, such as Wikipedia and Baidu Encyclopedia, and 20\% from news and articles that were published on web portals, such as SINA and Yahoo. Links from general business websites and personal websites or weblogs respectively accounted for $19 \%$ and $18 \%$ of all quoted links. Slight though the differences may be, the students tended to use more often statistics and text information from websites from categories 1 and 2, that is, government websites and online encyclopedias, and to use more videos and pictures from personal information sources, which indicates their ability to collect and use digital resources from different sources.

Second, the WCIL activities clarified student criteria in judging information. Although the students were confident that they knew how to choose information before they started WCIL, most of them acknowledged that through collecting information for the learning activities, their criteria for judging information became more sophisticated. In addition to common information evaluation criteria, such as considering the source and publishing date of the information, students began to reflect on whether the information was substantiated by sufficient and pertinent data, and whether it was clearly presented and well organized.

GL5: [When I am judging information from the Web,] I will examine whether enough data and details were offered in the web content to support its argument.

Third, WCIL helped in developing the basic ability of students to collect, analyze and synthesize information. Although this was the first time that the students had been asked to compose a multimedia inquiry report on a group weblog, all of the groups except for group 9 finished their inquiry report by integrating the multimedia materials collected from the Internet and through field work and showed various levels of ability to synthesize multimedia digital text. WCIL may also push students to acquire some comparatively advanced skills in information collection and analysis. To collect the necessary data for their inquiry learning projects, groups 1 and 7, for the first time in their learning experience, conducted a survey as part of their inquiry learning by using an online questionnaire and prepared data statistics and generated diagrams using Excel (a spreadsheet program). In doing so, they demonstrated proper awareness of and various skills in using digital technologies, including the ability to collect, analyze, and present first-hand information. 


\section{Improvement in the Ability to Create Multimedia Artifacts}

The students reported that they became more proficient in taking photos, editing video clips and creating multimedia artifacts.

GL5: I think we made big progress in video editing. Before taking part in this learning activity, I did not know how to organize a video clip and make it vivid. Now, whether the video is created using Photo Story ${ }^{I}$ or is a real video clip, I can make it flow through editing and thus it is more pleasurable to view, not as boring as before.

GL8: Yes, we did improve in this aspect [composing multimedia artifacts]. We now know how to choose the multimodal content for our inquiry report.

GL7: We think we are more skilled in presenting information through multimedia, because before this learning activity, we rarely used this form.

All nine groups that finished their inquiry reports used text and pictures. In addition, groups 2, 3 and 5 used videos and groups 1 and 7 used Photo Stories in their inquiry reports to present their inquiry learning results. This usage of multimedia demonstrates their newly developed ability to create multimedia artifacts.

\section{Online Communication Skills}

No indicator pointed to a significant improvement in the online communication skills of the students via digital technology. A possible explanation is that they were already accustomed to communicating with their friends on the Internet. In this study, the Microsoft Network (MSN http://www.msn.com/?st=1 ), email, Facebook (http://www.facebook.com) and weblogs were the main channels through which students communicated and shared inquiry resources with each other. Among the technologies, MSN was used more often than either email or weblogs, probably because the students could get an immediate response through this synchronous communication tool. Although most of the participants had a Facebook account and signed in every day, they used it mainly for gaming and connecting with friends and only rarely for learning. They also use IT School (an online platform offered by the school) to exchange resources of bigger memory size, such as photos and audio and video clips. Only $26 \%$ of weblog postings received feedback from other students, mainly because communication via weblog is asynchronous and less efficient and lacking in an immediate response compared to texting.

\section{Improvement in the Awareness, Attitude, and Ability to Use Digital Technology Appropriately}

First, WCIL aims to enable students to obtain a better understanding of the functions of digital technologies. The present study found evidence of such learning. For example, one student noted that they had learned that a weblog could function not merely as a diary but also as a useful tool to strengthen group inquiry learning.

GL2: I never thought that a weblog could be used to support group inquiry learning, but it really works! In the past, we used computers and the Internet mostly for entertainment, such as online news and games, Facebook and MSN. Now, to finish our inquiry learning on the web, we had to hold discussions online, collect information, share resources and

\footnotetext{
${ }^{1}$ Photo Story involves the creation of a video presentation that includes digital photos with pan and zoom effects, and narration, effects, transitions, and background music.
} 
compose our digital inquiry report on our weblog. We now use digital technologies much more often, and have begun to understand that they can do more things than we expected.

Research into educational weblogs revealed similar results; that is, one-year mandatory participation in educational weblogging could improve a student's understanding of all of the purposes of weblogging (Lui et al., 2006).

Second, by enabling students to experience the efficiency and convenience of digital technologies, WCIL reinforces their understanding of the use of these technologies. The participants of the present study came to realize that "the inquiry process is more clearly structured" (GL1), and that using digital technologies can help them "make better use of the information they have collected from different sources" (GL4). Some students regarded the digital inquiry report as a "more advanced way to present [material]" (GL3) because "presenting inquiry learning results with digital media is more efficient and convenient" (GL7).

Another finding of this study is that the enthusiasm of students for multimedia expression was strengthened after the first cycle of WCIL. More than half of the groups admitted that they had become bored with the traditional ways of presenting inquiry learning findings. By participating in WCIL, they became increasingly capable of employing digital technologies and could freely use multimedia, such as sound, image, video and text, to develop artifacts more sophisticated than those incorporating only text, pictures, and photos.

GL7: The form for us to present our inquiry results became more advanced and diversified with the use of multimedia.

GL1: When we use IT to make our inquiry report, we can use multimedia freely, and insert pictures, video and Photo Stories into our report.

Lastly, the students learned digital etiquette through WCIL. With online learning practice and the teacher's stress on the importance of copyright, the students formed the habit of quoting their source when they used other people's work and were beginning to consider copyright issues when using music files in editing video and making Photo Stories. After their teacher introduced Creative Commons to the class, all of the inquiry groups inserted Creative Commons licenses into their group weblogs. Also, before posting on weblogs or the web, they began to reflect on whether they might hurt others by what they wrote and, before posting new content on the group weblog, to consider whether their post (a) was closely related to the inquiry question and helpful for the group's inquiry learning or (b) strayed from the stand of their group or overlapped with the content posted by other members. These concerns indicate that the level of digital etiquette of students improved substantially.

\section{Obstacles to Digital Literacy Development}

The level of accuracy of accessing information of students was comparatively low, meaning that the students need to develop further their information searching strategies and searching skills.

GL6: The information collected from the Internet seems to stray away from our inquiry topic. Some information we posted on our weblog seems not to be closely related to our inquiry topic. This problem has affected the quality of our inquiry report.

GL6: The materials we found do not seem right on target, and cannot accurately answer the questions we are supposed to answer.

Another difficulty lay in collating and analyzing inquiry materials. The students reported that they needed more support in the stages of inquiry material collation and analysis.

GL8: I think we did not get enough support from the teacher during the collation and analysis of the inquiry learning material. 
GL8: We need more guidance and supervision as to how to analyze inquiry materials and organize them into a report.

Finally, extracting useful information from the collected material and synthesizing it to create a well-organized inquiry report was still problematic for students, as evidenced in their inquiry reports. First, despite the sufficient amount of material on the group weblogs, the content of seven inquiry reports was thin. Second, these inquiry reports had a somewhat patchwork nature. Similar problems were reported by Kuiper et al. (2009), who found that many students tried to find precise answers to their questions but lacked the skills to recognize and integrate pieces of useful information when they composed the answers themselves.

\section{Problems Faced by Students during WCIL}

\section{Poor group collaboration and low level of initiative}

Our study demonstrates that real collaboration is critical for the success of WCIL. The members of group 9, which failed to produce an inquiry report, lacked collaboration skills. In contrast, the groups in which members collaborated well were more likely to create high-quality inquiry reports at the end of the inquiry learning. Similar results are reported in the study of Kuiper et al. (2009), which found that the teachers who were the most successful in connecting the acquisition of critical web skills with the joint production of a brochure were those who paid explicit attention to collaboration. In the current research, the level of collaboration varied among the different groups. Five group leaders thought that their group collaboration was weak. They said that they had difficulties in leading the whole group and involving all of the group members in the inquiry learning activities. They also mentioned that some members were unwilling to take up their assigned tasks and tended to depend on the group leaders; as a result, the group leaders had to finish more of the tasks. Almost all of the work in making an inquiry plan was completed by the leaders in the groups characterized by poor collaboration. Although other group members may have provided feedback and comments, they seldom revised the inquiry plan themselves, but left the task to their group leaders. Work distribution also presented a problem for group leaders, especially in the case of a group the members of which were not familiar with each other. After the first round of WCIL, all of the group leaders said that the work distribution should be easier and more reasonable in the next round.

\section{Insufficient leadership skills of group leaders}

It is generally believed that leadership plays an essential role in collaborative learning groups (Northouse, 2007). Observing student participation in the WCIL activities, we found that the group leader is critical for the success of group collaboration. The statistics of student activity on the group weblogs show that of the ten most active students, five were group leaders. The other five group members were from groups whose members collaborated well. In those groups, group leaders were not only responsible for their own work but also played an important role in facilitating group work, such as giving comments and suggestions to other members regarding their posts, encouraging and praising the contributions of group members to the weblog, and organizing group discussions.

Eight group leaders stated that their leadership skills had improved through this process, but two leaders refused to be group leader again in the next round of inquiry learning because they found the heavy workload and pressure wearisome. The leaders of groups with good collaboration practices, however, did not have similar complaints. 


\section{Lack of inquiry learning experience and skills}

The first WCIL activities that students needed to accomplish were choosing an inquiry topic and developing inquiry questions. Although the teacher gave guidelines on how to choose an appropriate inquiry topic and the criteria of good inquiry questions, students still found it difficult to come up with a suitable topic and to develop reasonable inquiry questions from a broad field in which they were interested.

Another problematic task for students was selecting a suitable approach to solve the inquiry questions and to design instruments after the inquiry methods had been fixed. For example, when a survey or interview was adopted as the inquiry method, students had difficulties in designing questionnaires and interview questions. Even though they had studied the typical inquiry learning cases offered by the teacher and had understood the process of these cases, they still found it difficult to plan and complete their inquiry learning tasks.

In addition, the analysis of inquiry data and writing up of reports was tough for more than half of the groups. As the data collected by students might include both qualitative and quantitative data in the form of text, figures, and multimedia elements, the students, who lacked data analysis experience and report writing skills, were baffled by how they could draw reasonable conclusions through data analysis and structure and compose reports using the materials collected.

\section{Need to change the teacher's role}

Three groups reported that the teacher was over-involved in the process. One group leader stated, for example, "It seems that he [the teacher] is afraid that we cannot finish the inquiry learning activity, so he always tries to teach us how to do it, and sets many rules and steps for us to follow. This has, to some extent, restricted our work" (GL8). Students were willing to carry out the WCIL activities by themselves and tended to seek their teacher's help regarding only practical issues, such as improving group collaboration, drawing up inquiry questions, designing an instrument for their inquiry, and analyzing inquiry data. One student noted, "On-site support is better than the teaching of general rules" (GL5). Another study showed that in a Wiki-based collaborative learning activity, the teacher's role changed, from being solely an instructor to an organizer, leader, facilitator and supervisor of the activity (Zheng \& Zhuang, 2008).

\section{Discussion}

The social benefits associated with cooperative learning are well documented. It has been shown that cooperative learning can help to promote social relationships in groups (McMaster \& Fuchs, 2002; Slavin \& Cooper, 1999) and foster interpersonal skills (Cowie \& Berdondini, 2001). In this study, students also reported social benefits obtained through WCIL. For instance, they recounted significant improvement in such areas as collaborative ability, interpersonal skills, articulacy, ability to adapt, judgment, and the courage to carry out interviews and surveys with strangers. To finish the WCIL activities, students needed to participate in group discussions, do interviews, make on-the-spot observations, and conduct surveys outside the school. They were pushed to learn how to communicate with team members and the public and clearly present their inquiry learning results to their classmates. Some typical quotes follow.

GL6: I think this learning activity is really useful. We developed articulacy and the ability to adapt to changes and to make judgments. We have learned to be braver.

Group 1 weblog posting: Through this learning activity, I learned how to get on with other group members and collaborate with them.

Group 7 weblog posting: I learned how to get along well with others, and how to share the inquiry results with them. 
Group 10 weblog posting: I learned how to get along well and cooperate with others, and our friendship was strengthened.

Group leaders also reported the strengthening of their leadership skills through WCIL. Most of them said that they perceived significant growth in their ability to organize a group to carry out a task and to encourage group members to participate in and collaborate on the inquiry learning tasks.

GL8: Our performance should be much better next time, because we will do better in time allocation, work distribution, and collaboration.

GL2: Now I know how to get other group members involved and how to ask them to do inquiry work.

Participation in the WCIL activities also increased the depth and range of knowledge of students and widened their horizons. It was frequently mentioned by students in the reflection part of their inquiry reports that they had gained much knowledge about the inquiry topics. They also believed that inquiry learning gave them experience in learning things through on-site investigation, which was totally different from their previous school learning experience, and changed their view of learning. In addition, their inquiry learning results changed many of their established ideas.

Group 1 weblog posting: I have learned a lot outside books, and have come to realize that if you want to know a thing or a place thoroughly, you must go to the field to investigate it.

Group 1 weblog posting: This study made me understand that everything has its value for existence. We should see not only the appearance of things but also the deeper meaning behind them.

Students developed various inquiry learning skills through participating in WCIL, such as narrowing the realm of inquiry and generating inquiry questions, judging the value of inquiry questions, choosing a reasonable inquiry topic according to certain guidelines as well as planning and implementing an inquiry learning project.

GL7: I learned many inquiry learning skills, such as narrowing the inquiry topic and judging an inquiry topic according to its research value and interest.

Group 7 weblog posting: I've learned how to distribute inquiry work and complete an inquiry learning project through this activity.

Group 7 weblog posting: I learned many inquiry skills, such as doing interviews and collecting inquiry materials.

Taking on the various WCIL tasks also raised the awareness of students of the extent of their DL and inquiry learning skills, which is critical in the development of DL and such skills.

\section{Implications and Conclusion}

Judging from the learning results of the student participants in this study, it is reasonable to conclude that WCIL can provide a valuable context for the development of student DL. The improvement in the level of DL of students is significant, as they showed advancement in their ability to access and evaluate information, integrate multiformat texts, create multimedia artifacts, and develop an appropriate attitude toward digital technologies. The students also demonstrated significant progress in their inquiry learning and skills, collaboration, interpersonal and leadership skills, and knowledge about their inquiry topic. It should be noted that this study represents only a single case, and thus the findings may not be replicable in other educational settings. Further 
qualitative studies and quantitative measurements are needed to clarify the effect of WCIL on student DL.

The problems that the teacher and students encountered during WCIL included (1) inadequate DL, which was mainly manifested as the difficulties that the students had in analyzing and synthesizing inquiry materials, and in improving the level of their accuracy of accessing information; (2) lack of effective collaborative learning within each group; and (3) lack of inquiry skills and experience. Based on the aforementioned problems, it is recommended that in the implementation of WCIL, the following points be taken into consideration. First, it is important to make sure that the group leader has previously demonstrated leadership qualities and a strong sense of responsibility, as the group leader is critical for group collaboration. Second, the weblogs of groups with good collaboration practices can be reviewed in class to stimulate collaboration in other groups and between-group competition. Third, in the implementation of WCIL, teachers may need to shift their role from teacher to facilitator. They should clearly state the purpose, tasks, and requirements of the WCIL project at the very beginning and supervise the inquiry learning process. A suggested model for use in class time features presentations by students of their progress, with the teacher providing comments and suggestions. Supervision of the learning process of students not only gives them the opportunity to learn from each other but also encourages timely suggestions for the projects by the teacher, which may be more helpful than instruction in general inquiry skills. In summary, teachers implementing WCIL should function like football coaches: they need to state the purpose and clarify the requirements of the project at the beginning, and then give guidance and suggestions throughout the whole process based on the performance of students.

\section{References}

Bell, T., Urhahne, D., Schanze, S., \& Ploetzner, R. (2010). Collaborative inquiry learning: Models, tools, and challenges. International Journal of Science Education, 32(3), 349-377. doi:10.1080/09500690802582241

Buckingham, D. (2003). Media education: Literacy, learning and contemporary culture. Malden. MA: Blackwell Publishing.

Campbell, M. A. (2005). Cyber bullying: An old problem in a new guise? Australian Journal of Guidance \& Counseling, 15(1), 68-76.

Chang, K-E., Sung, Y-T., \& Lee, C-L. (2003). Web-based collaborative inquiry learning. Journal of Computer Assisted Learning, 19, 56-69.

Cowie, H., \& Berdondini, L. (2001). Children's reactions to cooperative group work: A strategy for enhancing peer relationships among bullies, victims, and bystanders. Learning and Instruction, 11, 517530 .

Doering, A., Beach, R., \& O’Brien, D. (2007). Infusing multimodal tools and digital literacies into an English education program. English Education, 40(1), 41.

Eshet-Alkali, Y., \& Amichal-Hamburger, Y. (2004). Experiments in digital literacy. Cyber Psychology \& Behavior, 7(4), 421-429.

Erstad, O., Gilje, Ø., \& Lange, T. (2007). Re-mixing multimodal resources: Multiliteracies and digital production in Norwegian media education. Learning, Media and Technology, 32(2), 183-198.

Educational Testing Service of America. (2002). Digital transformation: A framework for ICT literacy. Retrieved July 20, 2010, from http://www.ets.org/Media/Tests/Information_and_Communication_Technology_Literacy/ictreport.pdf

European Commission. (2003). eLearning: Better eLearning for Europe Directorate-General for Education and Culture. Luxembourg: Office for Official Publications of the European Communities. 
European Union. (2006). Recommendation of the European Parliament and of the Council of 18 December 2006 on key competences for lifelong learning. Official Journal of the European Union 10-18. Retrieved April 20, 2010, from http://eurlex.europa.eu/LexUriServ/LexUriServ.do?uri=OJ:L:2006:394:0010:0018:en:PDF

Gilster, P. (1997). Digital literacy. New York: Wiley Computer.

Hartley, J., McWilliam, K., Burgess, J., \& Banks, J. (2008). The use of multimedia: Three digital literacy case studies. Media International Australia, $\operatorname{Aug}(128), 59-72$.

Horton, F.W., Jr. (2007). Understanding information literacy: A primer. Retrieved June 25, 2009, from http://unesdoc.unesco.org/images/0015/001570/157020e.pdf

Kuiper, E., Volman, M., \& Terwel, J. (2009). Developing web literacy in collaborative inquiry activities. Computers \& Education, 52, 668-680. doi:10.1016/j.compedu.2008.11.010

Luce-Kapler, R. (2007). Radical change and wikis: Teaching new literacies. Journal of Adolescent \& Adult Literacy, Nov, 214-223.

Lui, A. K. F., Choy, S. S. O., Cheung, Y. H. Y., \& Li, S. C. (2006). A study on the perception of students towards educational weblogs. Informatics in Education, 5(2), 245-266.

Martin, A. (2008). Digital literacy and the "digital society". In M. K. Colin Lankshear (Ed.), Digital literacies - Concepts, policies and practice (p. 151-176). New York: Peter Lang Publishing.

McMaster, K., \& Fuchs, D. (2002). Effects of cooperative learning on the academic achievement of students with learning disabilities: An update on Tateyama-Sniezek's review. Learning Disabilities Research and Practice, 17, 107-117.

Midoro, V. (2007). Literacy for the knowledge society. Paper presented at the 3rd International workshop on Digital Literacy.

Northouse, P. G. (2007). Leadership: Theory and practice (4th ed.). Thousand Oaks, CA: Sage Publications.

Ofcom. (2009). Media literacy audit: Report on media literacy amongst children. Retrieved June 30, 2009, from http://www.ofcom.org.uk/advice/media literacy/medlitpub/medlitpubrss/children/

Owston, R., Wideman, H., Ronda, N. S., \& Brown, C. (2009). Computer game development as a literacy activity. Computers \& Education, (53), 977-989.

Slavin, R. \& Cooper, R. (1999). Improving intergroup relations: Lessons learned from cooperative programs. Journal of Special Issues, 55, 647-663.

Soby, M. (2008). Digital competence - From education policy to pedagogy: The Norwegian context. In M. K. Colin Lankshear (Ed.), Digital literacies - Concepts, policies and practice (pp. 119-150). New York: Peter Lang Publishing.

Tapscott, D. (2009). Grown up digital: How the net generation is changing your world. New York: McGraw-Hill.

Young, K. S. (1996). Internet addiction: The emergence of a new clinical disorder. CyberPsychology \& Behavior, 1(3), 237-244. doi:10.1089/cpb.1998.1.237.

Zheng, B. B., \& Zhuang, X. L. (2008). Wiki-based collaborative learning activity design: A case study. Proceedings of 2008 International Conference on Computer Science and Software Engineering, 141145. DOI 10.1109/CSSE.2008.954. 


\section{Biographies}

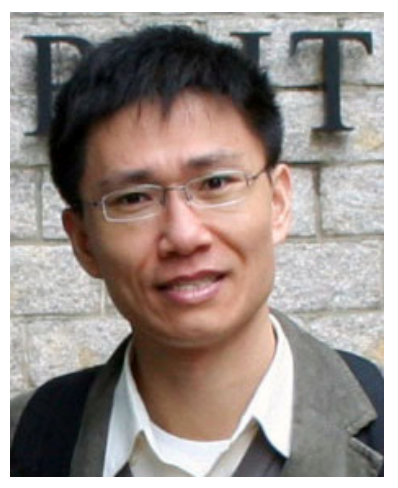

FU Jun is a lecturer in the School of Educational Technology, South China Normal University. He received his M.Phil. in the Department of Education Studies, Hong Kong Baptist University. His research interests include media literacy education, digital literacy education, and application of ICT in teaching and learning.

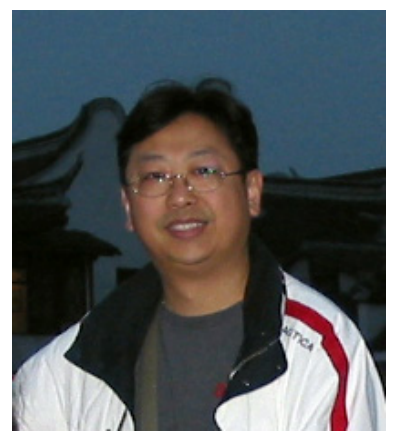

Jacky Pow is an assistant professor in the Department of Education Studies at the Hong Kong Baptist University. He received his M.Sc. from the University of Sheffield, M.Phil. from the City University of Hong Kong, Ph.D. from the University of Nottingham, and PGDE from the University of Hong Kong. He has a research and professional interest in innovative pedagogies and enhancement of learning and teaching with technologies. 